\title{
Material activism. New hybrid scenarios between design and technology
}

\section{Rognoli, Valentina; Ayala Garcia, Camilo}

Resumen: La década pasada es, según algunos académicos, caracterizada por una onda hacia una nueva revolución industrial [1].

Principalmente gracias al hecho que la tecnología ha salido del dominio de la industria para quedar en las manos de la gente común. Los materiales están poco a poco comenzando a presentar el mismo tipo de comportamiento, dado que hoy en día mas y mas personas están experimentando con la creación de materiales de manera disruptiva. Este artículo presenta el concepto de Activismo Material como mecanismo para entender el fenómeno en crecimiento que esta permitiendo a los materiales democratizarse a través de una aproximación de base.

\section{Cuadernos del Centro de Estudios de Diseño y Comunicación N ${ }^{070}$}

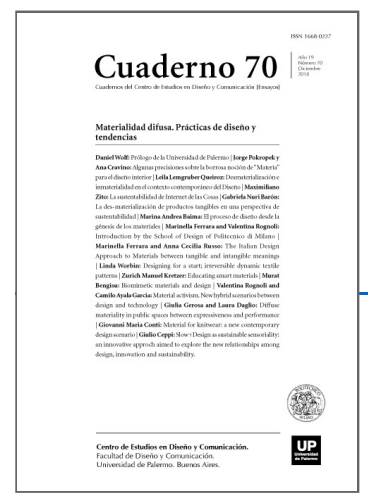

ISSN: 1668-0227

Materialidad difusa.

Prácticas de diseño y

tendencias

Año XIX, Diciembre 2018, Buenos Aires, Argentina | 172 páginas

descargar PDF

ver índice de la publicación

Ver todos los libros de la publicación

compartir en Facebook

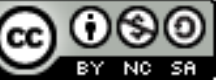

Esta obra está bajo una Licencia Creative Commons Atribución-NoComercialCompartirlgual 4.0 Internacional

Palabras clave: democratización - conocimiento compartido - tecnologías poco sofisticadas - hacking - auto producción y hazlo tu mismo.

$\left(^{*}\right)$ Designer, PhD in Industrial Design and assistant professor at the Design Department of the Politecnico di Milano. She has been working in the field of materials for design for almost twenty years gaining expertise on this topic both in research and education. She has always been interested on the expressive-sensorial dimension of materials and their emotional aspects.

$\left.{ }^{* *}\right)$ Ph.D. Candidate - Politecnico di Milano, Italy. Assistant Professor - Design Department Universidad de los Andes Bogotá, Colombia.

1. Introduction

Our material experience (Giaccardi \& Karana, 2015) is, thanks to the materials, artifacts and objects that surround us, a conditioned experience. It is ruled by the fact that everything we enter in contact with, come from 
an industrial mass production. That is to say that our material experience is based mainly from industrial materials that have been developed to be coherent with shapes efficient in a mass productive system. This is the result of decades and decades of development of the industry and will not change in the immediate future (Rognoli et al., 2015) although other remarkable phenomena are emerging.

We have witnessed in the past 15 years an exciting change of scope when it comes to the understanding of the relationship between design and technology in a contemporary world. Materials influence tremendously that relationship back and forth as they are embodied in everyday artefacts through mass production. We are surrounded by industrial materials industrially processed. There are two main established forces that drive materials development:

On one side we have the search for solutions to the technical/technological problems in strategic sectors like medicine or military, and on the other side the research of more affordable materials solutions that can be scaled up easily to fulfill industrial demands (Lindstrom, Razavi \& Nobell, 2014). This established forces of materials development are starting to see a third one coming that is going to establish as well; the one that deals with biobased materials development to fulfill environmental affairs. Another important issue that drives material development throughout industry, is around the concept of Material Surrogate (Rognoli \& Levi, 2015). This concept states that through history all materials in different scales have been replaced by other materials, that in the beginning of their development and application were considered surrogate: precious stones were replaced by glass, Majolica clay or porcelain were take over by terracotta, Ivory and turtle shell by Plastics. The value attributed to a surrogate material is not only economical, but also expressive, which refers to quality, aesthetics and the imaginary of the matter itself. Surrogate materials can be understood also as materials that imitate other materials, therefore they lack on language innovation. This panorama is very common in the industrial materials world. Important to underline though, is the fact that the new materials that substitute others should be compatible with the technologies and processes available in order to improve possible applications and enter in the more efficient way, the industrial system. This approach becomes very unstimulating to designers as the expressive sensorial qualities of materials (Rognoli, 2004) become alike among them and no room for innovation can sparkle.

An additional relevant consideration is that during the process of materials development, the designers seldom enter into the development team, in the main composed by Engineers and Scientists. In this exclusive rigid industrial system with a large amount of entrance barriers, designers have been used to employ materials and processes already available in the market as they rarely contribute in the development of any particular material. In other words, designers have become experts in material selection or select materials thanks to instruments available, as no other source appears at hand.

One of the instruments available for designers regarding selection are the materials libraries. In the past twenty years we have witnessed a growing interest among designers to become closer to the materials domain that was took apart from our discipline founded with deep roots in crafts and physical experimentation with materials. Thanks to the scientific materials development that closed materiality in laboratories and in Industry R\&D sections for almost half of a century, few or no room remained for several generations of designers to interact with materials aside from the selection perspective. To this point material libraries become a display of materials that come from an industrial mass production systems and therefore our expressive sensorial possibilities (Rognoli, 2004) of application are limited with what the industry can provide. 
The opening of material libraries has been a key point in the design field as they have triggered once again a closeness relationship between materials and designers, considering that they were already excluded form the closed engineering and scientist materials development circle. Those libraries opened a chance for designers to get in contact with hundreds of materials samples in the same place allowing themselves to contribute to the project by understanding the properties of a material available on the market. Mainly the contribution appears as the designer is capable of extract the expressive-sensorial qualities of a material sample and therefore perform the right selection for a particular application or take them as a source of inspiration to develop a new project. Many industries recognize this ability as part of the CMF (Color, Materials and Finishes) domain where designers are capable to deal with the sensorial attributes of materials and finishes to support both functional and emotional attributes of products. Liliana Becerra (2016) states that "the work of the CMF designer combines aesthetics and practical knowledge of materials and technologies with intangible human perceptions of value". Although this domain is growing and catching interest among designers, we believe it cannot be the only place where designers can get in contact with the materials development system.

\section{Material activism}

We introduce the concept of activism as a provocative exhortation to the designers in order to start a vigorous protest against this closed system of materials development, that exclude designers on the basis of lack of knowledge on one side and a dependence on the system to select the materials for a project on the other side. The term materials activism was firstly coined by Miriam Ribul (2014) as an expression to identify a lowtech approach that will democratize the production and development of materials. In her open source publication, the author invite through a collection of recipes for in-house material experimentation, to understand how its possible to develop alternative models to replace traditional industrial ones, creating also new aesthetics and innovating through new materials languages.

What comes into evidence and will later become our target on the discussion in this paper, is that the approach and all the examples that will be presented here shows the emergence of another way to see materials and processes. An alternative and parallel view that carries within a new dimension of the relationship between designers, technology processes and materials. The key words that emerge from this alternative material approach such as democratization, sharing, low-technologies, hacking, self production and Do-lt-Yourself, very contemporary terms of the second decade of the XXI century, interconnect to configure a very precise context and a particular approach to the project that consider above all the hands on technique and a new way of tinkering with materials (Jacobsson, 2013; Karana et al., 2015). The interrelation of those factors have given the possibility to this new or emerging materials experiences (Karana et. al, 2014) to emerge.

The new appreciation of being an artisan, the acceptance of Do-lt-Yourself practices as a possible practice within the society, supported thanks to the internet and the opensource philosophy (Anderson, 2012, p. 58) became the fertile ground that gave the proper goldilocks conditions for materials activism to appear. The democratization of the means of production, combined with the people`s wish for personalization (Anderson, 2012, p. 102) have opened an alternative to the closed system of industrial materials development. A designer can feel right now the will to go home, enter into the kitchen and start any materials experimentation experience that may find interesting in any website. After some iterations with the material it may also will go and buy any open-sourced instrument that can help improve what have created. Suddenly this designer will be part of this emerging group of activists that create a project starting with the material development. 
That possible scenario was not so long ago impossible to imagine as materials and processes were developed and improved inside a closed system inside labs and Industry's R\&D sections and not in a home or workshop. (Figure 1)

We have always argued in the field that designers are multi-disciplinary entities as we share some capabilities with other fields in Social Sciences, Arts or Engineering. But based on our premises of this introduction, we can state also that today the designer can be seen better a trans-disciplinary entity. That means that the designer can work transversally with other disciplines collaborating in their will to understand the complexity of a problem to tackle. Designers are now open to biology, chemistry, medicine, math's. Not as a person to confront Humanities and Science but a bridge to connect them, specially when it comes to materials world.

\section{The material activists}

By stating that designers in the role of activism when it comes to materials development, are triggering new scenarios, it is wise to say that part of that role in a trans-disciplinary way, is to become some times artisan, sometimes chef, sometimes an alchemist.

The word alchemist is what is going to introduce this part of the study where several types of materials activists are shaping the phenomena around the globe. We are presenting here briefly three activists we consider started to make visible in an structured way the phenomena we have been discussing in this manuscript.

\section{Material alchemy}

The first one, and the one who published a book with this name Material Alchemy, Jenny Lee (2015) states in her book how from a trans-disciplinary point of view materials for design are growing worldwide. As a declaration in the book, "is how to redefine the materiality of the XXI century". Which means, what is the concept of materiality that emerge from the materials that can be developed today. Interesting from this activist approach is to understand how these materials can be developed from an alchemist manner.

We believe it is a clever asset to bring Alchemy concept into this phenomena, based on the fact that Alchemy as a form of Chemistry and speculative Philosophy practiced in the Middle Ages and the Renaissance was engaged principally with the discovery of different methods to transform matter. One of the aims was to transform Lead, which at that time and even today is a material associated with bad and negative outcomes into Gold which on the contrary is perceived as the perfect material and the representation of a greater good. To change from evil to holy, from what is bad into something superb. In this contemporary activist approach, it is interesting to see how this alchemist intent remains as one of the key drivers for designers that enroll in materials development where one of the main aims is to change industrial waste into a valuable material once again. (Figure 2) Another valuable issue that can be pulled out of the Alchemist metaphor through the idea of transforming what is bad into something better, is the possibility to gain independence. We believe that designers who experiment with materials through this activist approach, are gaining several material knowledge that provide a certain amount of independence from the closed system of traditional material development.

The complete collection of cases presented in the book Material Alchemy can be seen with this perspective as well. All the material samples provided by a collective of designers have in common in one way or another, the 
willing for a change. The change that independence from traditional materials developing systems can provide. The more independent designers are to develop a project by starting with the materials source, the further can go with the goal achievement. This goal of a designer, different form any other discipline, is that can be systemic, which means it can tackle different sides of the project at the same time. When a material alchemist starts the project by transforming matter into a purposed goal, not only creates an artifact; it studies the relationship between the artifact and the user, the environment, the life cycle and the afterlife of it. That perspective is what enlighten our research on material development within the design field.

Of course designers cannot do it alone. It will be simply not possible to achieve such goals without the support and collaboration of other areas of knowledge. That's why the transdisciplinary approach illustrated in this publication shows examples from biology to new technologies where designers and scientist get involved together as collaborative partners redefining the materiality of the 21 st century.

\section{Cooking materials}

Another recent example of material activism is found in the work of the Belgian Laurence Humier (2012) who for some years started a research called cooking materials, in which the hybridation between design, material physics and molecular gastronomy (a discipline that studies the transformation suffered by aliments during the preparation stages, aiming to transform cooking empirical knowledge into a true and proper science). In the words of one of the founders of this area of gastronomy Hervé This (2006, p. 2) "Molecular gastronomy deals with culinary transformations and the sensory phenomena associated with eating". When looking the definition of molecular gastronomy, one can immediately connect the kitchen domain with the design domain. Both create, transform matter to create sensorial experiences through products. In fact, there is a strong connection between the manufacturing processes of the industry and the ones of the professional kitchens. Some of them can be used to teach designers how to produce things by understanding the principles of the cooking crafts (Ayala, 2015). With industrial waste as ingredients, blenders and ovens as instruments, Humier presents a collection of recipes in which the material world is explored with this novel approach. In other words, composing from the molecular basis the matter of these ingredients to develop new materials. (Figure 3 )

\section{Open materials}

The last example of materials activists in which a novel approach can be perceived is called Open Materials from the social scientist Catarina Mota (2009). Here is visible through the relationship between design and technology, through the so called smart materials, how it is possible to develop trough an open source platform, a research around materials and applications with the aid of Do-it-Yourself techniques. The research team leaded by Mota, present in a virtual platform all different experimentations guided by the open-sourced approach to materials development. Many of the developments presented come from what is known the makers Movement. The maker's movement began when the Do-it-yourself culture, who was a result of the cottage industry of the British XIX century met the web culture of the end of the XX century (Anderson, 2012, p. 72). That is what is known these days as the new industrial revolution, where thousands of makers working together in an open source model create a new kind of manufacturing economy (Anderson, 2012, p. 67). Catarina Mota states that "if we are to live in a world made of smart materials, we should know and understand them" (Mota, 2013). This statement invites, as part of the maker's movement philosophy, to hack knowledge of science and put it into the hands of "non experts". Designers are adapting this methodologies of hacking as a way to understand how the world is 
made so maybe it will be possible to make it better. Jonathan Lukens states that the DiY subculture is able to do things that work better than the classical infrastructure of the society (Lukens, 2013), therefore, everybody who gets involved in the movement like Catarina Mota, regardless of the background as social scientist instead of being trained as designer, is invited to re-think the infrastructure of the society and propose new ways of improving our world. (Figure 4)

\section{Discussion}

The previous examples of materials activists presented above, have served to introduce the phenomenon in which contemporary designers are demonstrating the will of compose, develop, transform, modify and self produce their own materials. This emerging phenomena can be better defined under the category recently known as Do-it-Yourself Materials (Rognoli et al., 2015). The DiY Materials are defined as materials developed through techniques of self production (individual or collective) with low technologies, easy accessible material sources and with an aesthetical language that evokes the craftsmanship and imperfect of its conception. Can be a new materials development or a modification of an existing material source. The development of DiY Materials is characterized by the integration of the development and production phases, combined with the autonomy that the designer can acquire in production by accessing the three examples of material activism described above.

Although Do-it-Yourself Materials are realized by informal and non-industrial producers outside the traditional companies and laboratories (can be called no-corporate materials as well), they might inspire scientists and engineers inside a company to go further in the development and scaling of the proposed material.

The panorama of industrial materials development is nowadays quite uninspiring and unexciting from the design perspective since the lack of stimuli for designers appears due to certain absence of scientific knowledge. We have argued that designers do not enter or rarely intervene into these logics of scientific materials development, therefore, this approach of self production of materials is favoring designers as empower them to become the promoters of a new material development. This activist materials approach of self production is allowing designers not only to "rebel" to the actual industrial system. It allows them to create and project from the beginning, the material experience that they desire. The material experience then will be born with the material contrary to what has happened form several years where designers at the last link in the chain were called to project the expressive-sensorial dimension of an industrial material already developed by someone else.

This is an enormous change of perspective for the design field when it comes to materials knowledge. Think globally, fabricate locally (Gershenfeld, 2012) becomes now more than ever of superb importance in terms of materials activism as invites to create the materials with what is known as Kilometer Zero impact, a term coined by the food industry (Cavanaugh, 2016). By sharing the knowledge, no matter when the idea comes, the material can be locally developed.

\section{Conclusion}

This paper has introduced and defined the new concept of Material Activism as an extension of what has been previously defined as Do-It-Yourself Materials (Rognoli et al., 2015). 
Through the analysis of three main actors around this phenomenon, we aimed to illustrate the relevance and the opportunities that these movement is representing for the design field. We have argued and discussed the key elements that are driving designers to take part in this new industrial revolution wave. Although Material Activism is a very novel concept it is important to study it properly as it will represent a balance in the future of materials development in the upcoming years. We believe that the research of materials development from the design perspective will allow designers to achieve a broader, richer future in complete equilibrium with the planet when creating artifacts and their emerging material experiences. Everything that will be created by following this phenomenon we described, will me full of meaning and value. Therefore, we believe people will be more attached to what will be produced redefining the goals and scopes of mass production and product life cycles in the future.

\section{References}

Anderson, C. (2012). Makers-The New Industrial Revolution. Random House Business Books.

Ayala, C. (2015). The Basis of Processes - Experimenting with Food to Re-Shape the Industry Language. In: Proceedings of Cumulus Conference, The Virtuous Circle: Design Culture and Experimentation. Milan: McGrawHill Education.

Becerra, L. (2016). CMF Design - The Fundamental Principles of Colour, Material and Finish Design. Frame Publishers. Cavanaugh, J. (2016). Talk as work: Economic sociability in Northern Italian heritage food production. Journal of Language and Communication 48,41-52.

Gershenfeld, N. (2012). How to Make Almost Anything. The Digital fabrication revolution. In Foreign affairs November/December 2012

Giaccardi, E. and Karana, E. (2015). Foundations of Materials Experience: An Approach for $\mathrm{HCl}, \mathrm{CHI} 15$ Proceedings of the 33rd Annual ACM Conference on Human Factors in Computing Systems, pg. 2447-2456.

Humier, L. (2012). Cooking Material. Could Molecular Gastronomy Help Discover New Matter? E-Book of Exhibition on Triennale Design Museum, Milano.

Jacobbson, M. (2013). Thinkering with Interactive Materials: Studies, concepts and prototypes. Royal Institute of Technology. Karana, E.; Barati, B.; Rognoli, V. \& Zeeuw van der Laan, A. (2015). Material driven design (MDD): A method to design for material experiences. International Journal of Design, 9(2), 35-54.

Karana, E.; Pedgley, O.; Rognoli, V. (2014). Materials Experience: Fundamentals of Materials and Design. Elsevier.

Lindstrom, M.; Razavi, F.; Nobell, N. (2014). The superhero and the DJ: Science meets design. Journal of Professional Communication 3(2), pp. 125-136.

Lukens, J. (2013). DIY Infrastructure. Georgia Institute of Technology. 
Mota, C. (2012). “Open Materials homepage. Open source materials collection”. Retrieved from http://openmaterials.org.

Mota, C. (2013). Open Sourcing Materials. In The Open Book. Eds. Kaitlyn Braybrooke and Jussi Nissila. The Finnish Institute in London.

Pedgley, O.; Rognoli, V. \& Karana, E. (2015). Materials Experience as a Foundation for Materials and Design Education. International Journal of Technology and Design Education, vol. 25; DOI 10.1007/s10798-015-9327-y

Rognoli, V. (2004). I materiali per il design: un atlante espressivo-sensoriale. Politecnico di Milano.

Rognoli, V.; Bianchini, M.; Maffei, S.; Karana, E. (2015). DIY Materials. Materials and Design, 86(2015), 692-702.

Rognoli, V.; Levi, M. (2005). Materiali per il design. Espressività e sensorialità. Milano: Polipress.

Ribul, M. (2013). Receipts for materials activism. Retrieved from: https://issuu.com/ miriamribul/docs/miriam_ribul_recipes_for_material_activism/ch1j

This, H. (2005). Molecular Gastronomy: Exploring the Science of Flavor. Columbia University Press.

Abstract: The past decade it is considered by many scholars as the new industrial revolution wave [1], mainly by the fact that technology has jumped out of the industry into the hands of the people. Materials are also starting to perform the same behavior as more and more people are starting to deal with the creation of materials in a disruptive way. In this paper we present the concept of Material Activism as a way to understand the growing phenomena that is allowing materials to democratize through a bottom up approach.

Key words: democratization - sharing - low-technologies - hacking - self production and Do-It-Yourself.

Resumo: A década passada é, segundo alguns acadêmicos, caraterizada por uma onda até uma nova revolução industrial, devido ao fato que a tecnologia saiu do domínio da indústria para ficar nas mãos das pessoas comuns. Os materiais estão pouco a pouco começando a apresentar o mesmo tipo de comportamento, já que hoje mais e mais pessoas estão experimentando com a criação de materiais de modo disruptivo. Este artigo apresenta o conceito de Ativismo Material como mecanismo para entender o fenômeno em crescimento que está permitindo aos materiais democratizar-se através de uma aproximação de base.

Palavras chave: democratização - conhecimento compartilhado - tecnologias pouco sofisticadas - hacking - autoprodução - faça-você-mesmo

Material activism. New hybrid scenarios between design and technology fue publicado de la página 105 a página115 en Cuadernos del Centro de Estudios de Diseño y Comunicación №70 